\title{
Pathology of the peripheral nerves in leprosy: report of a case
}

\author{
A. D. DAYAN AND U. SANDBANK \\ From the Department of Neuropathology, Institute of Neurology, Queen Square, London, and the Department \\ of Pathology, Beilinson Hospital, Petah Tiqvah, Israel
}

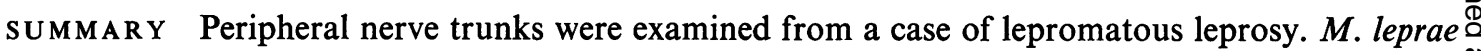
was seen in the nerves in several types of cells. Isolated nerve fibre preparations showed demyelinat- $ڤ$ ing lesions due to Schwann cell damage and complete nerve fibre degeneration. The causes of this $\vec{\circ}$ mixed pattern of damage may involve both a direct effect of the bacilli on nerve fibres and various epiphenomena.

Peripheral neuropathy is a characteristic feature of leprosy and, as such, has been known for many centuries (Cochrane, 1964a). The histological features of the affected nerves as displayed by conventional techniques (Virchow, 1864; Lie, 1894; Krücke, 1955; Khanolkar, 1964) have shown leprosy bacilli in nerve trunks, granulomatous inflammation, and varying degrees of damage to myelin sheaths and axis cylinders. Certain clinical features and the results of electrophysiological tests of nerve conduction (Jopling and Morgan Hughes, 1965; Rosenberg and Lovelace, 1968) have been interpreted as evidence for the occurrence at some stage of segmental demyelination, as well as of total nerve fibre degeneration.

We have investigated this point in one patient with lepromatous leprosy by examining isolated nerve fibres dissected by freehand teasing.

\section{CASE HISTORY}

A 77-year-old Iraqui male had lived in Israel for 16 years. For one year before death he was noticed to have ulceration of the finger tips, which seemed to be anaesthetic. They were often burnt when he smoked cigarettes, although he did not notice or complain about this. At this time the patient refused to be examined by a doctor.

Ten days before death he developed a severe purulent throat infection which was treated with streptomycin and ampicillin. After three days he became very ill and had a severe, generalized vesicular eruption. On examination then he showed the features of acute toxic epidermal necrolysis (Lyell's syndrome); hair had been lost from the lateral parts of both eyebrows; there were nodular thickenings of various sizes in both ear lobes; the tips of most fingers were ulcerated and anaesthetic; and, at the elbows, the ulnar nerves were thickened and tender. Smears from nodules in the ears showed numerous acid- ir fast organisms with the morphological characteristics gio leprosy bacilli $(M$. leprae).

Despite symptomatic treatment the acute skin lesiogs progressed and the patient died seven days after admissi@ to hospital.

At necropsy the body was that of a well-nourished man. Besides the acute skin lesions there was sevefe bronchopneumonia: the liver and several groups of $\mathbb{\Phi}$ peripheral lymph nodes were enlarged, and major ner $\overrightarrow{0}$ trunks everywhere were thickened. Histological examina $a^{+}$ tion revealed many granulomatous lesions containing. innumerable sheaves and clumps of acid-fast bacilli in pale, foamy ('Virchow') cells in the skin, liver, spleen, kidneys, and lymph nodes. There were also arteritic lesions in some of the viscera, in which part of the walls of medium-sized arteries contained similar inflammatory foci. Amyloid was not found in the viscera. The brain and spinal cord appeared normal in survey sections.

PERIPHERAL NERVOUS SYSTEM Formol-fixed samples of the main trunks of ulnar, sciatic, and femoral nerves? were examined. They were taken respectively from the forearm, at mid-thigh, and the femoral triangle.

Standard histological sections of paraffin-embedded and frozen material showed a variable loss of nerve fibres and some endoneurial fibrosis (Fig. 1). Intraneural granulomatous inflammation was rarely found and $\mathrm{O}$ arteritis was not seen in the nerves. Wade-Fite stained $₹$ sections of all three nerves revealed occasional clumps $ᄋ$ and isolated rod-shaped acid-fast bacilli which appeared to be in Schwann cells and other intraneural cells (Fig. 2), although their presence in axis cylinders could not be excluded with certainty.

Single nerve fibres were teased from all three nerves after impregnation with osmic acid (Dayan, 1967). Direct examination of the fibres showed mainly the $\tilde{\omega}$ 


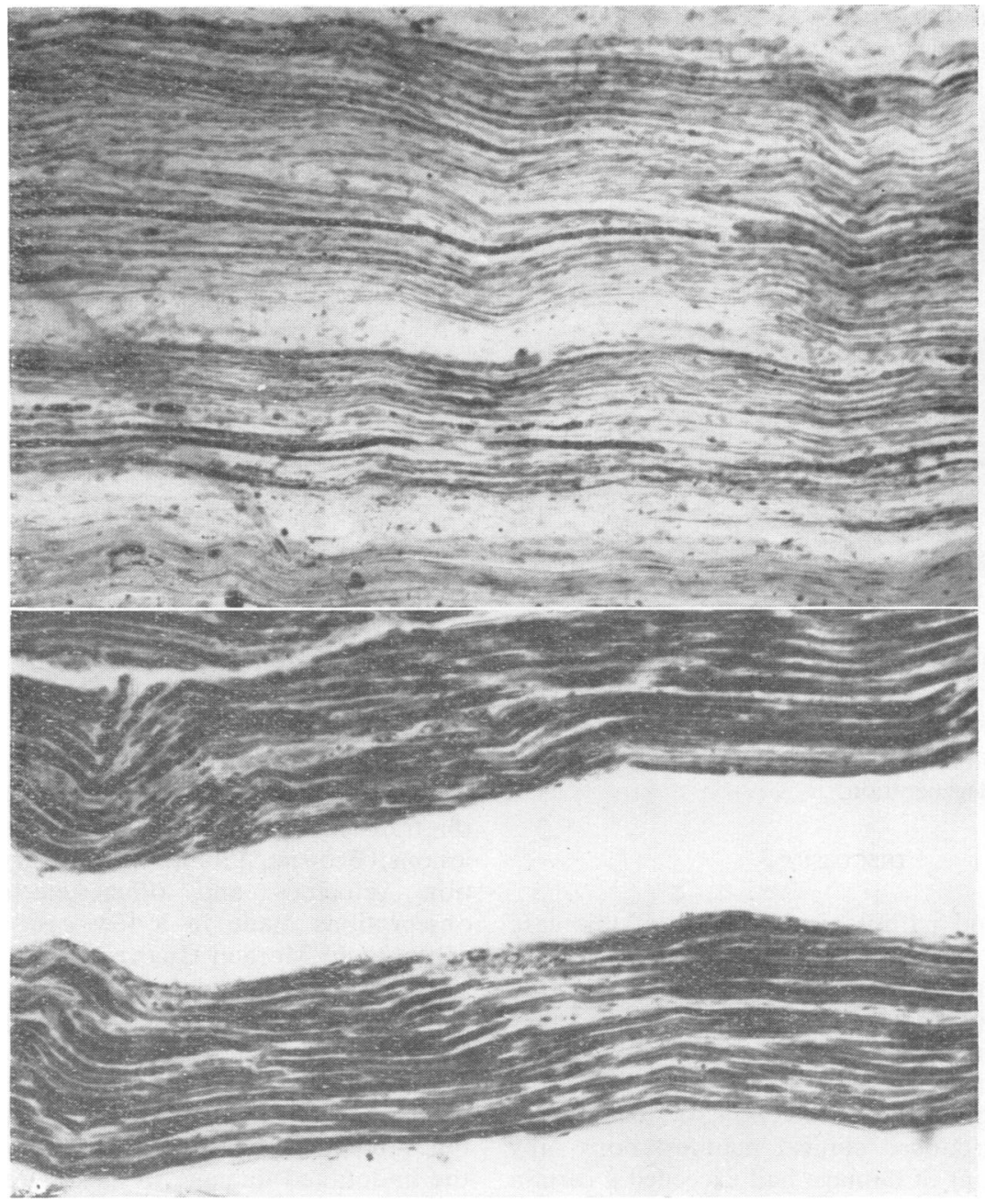

FIG. 1(a) and (b). (a) Above: fascicle of nerve showing loss of and damage to myelinated fibres. Frozen section. Sudan black, $\times 100$. (b) Below: active degeneration in part of sciatic nerve. Frozen section. Sudan black, $\times 75$.

lesions of segmental de- and remyelination (Fig. 3). There were some widened internodes and completely denuded segments. Other fibres showed abnormally short and thinly myelinated segments which were interpreted as stages in the healing of damaged internodes. There was a small number of nerve fibres with segments uniformly too short for normal fibres of their diameters, and these were considered to represent regeneration after complete Wallerian-like degeneration of the axis cylinders and their associated Schwann cell-myelin sheaths. Acute damage of this type was not found.

An attempt was made to stain isolated, unimpregnated fibres by the Wade-Fite and Ziehl-Neelsen techniques. However, very few fibres remained intact after the mani- pulations involved and it was impossible to identify bacilli in these preparations with any certainty.

The relationship between nerve fibre diameter and internodal length was determined by measurements made under direct vision and typical findings are displayed by the convention of Fullerton, Gilliatt, Lascelles, and Morgan-Hughes (1965) in Fig. 4. There is an abnormally wide variation of segmental lengths on individual fibres, which is typical of active and healed segmental demyelination. The amount of scatter and the high proportion of affected fibres is evidence of very extensive damage and repair which have probably occurred over a considerable period. Confirming the results of direct observation there were few fibres showing the uniformly shorter 


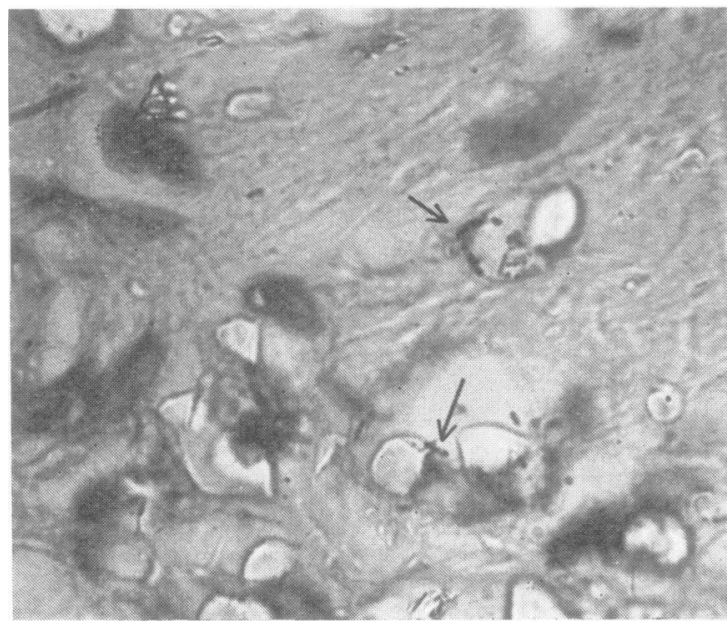

(a)

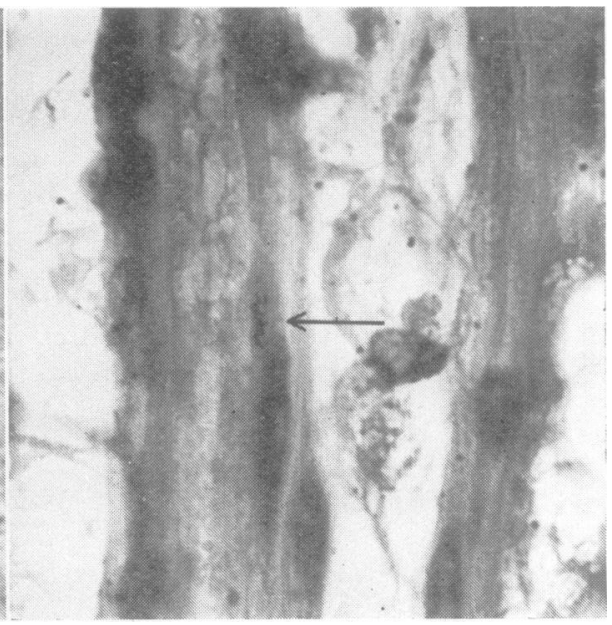

(b)

FIG. 2(a) and (b). Acid-fast bacilli (arrows) are present inside elongated cells in the nerves. Wade-Fite, $\times 1,000$.

than normal internodes produced by healing after Wallerian-like degeneration.

\section{DISCUSSION}

The clinical and pathological features of this case were typically those of lepromatous leprosy, and it was unusual only in the age of the patient when the disease became apparent. Such a late clinical onset and indolent course are often encountered in elderly patients (Cochrane, 1964b). It seems likely that he had been harbouring the infection for many years and that it produced clinical manifestations only after the amount of damage had exceeded a certain threshold.

Pathologically, two types of nerve lesions were found-that is, selective damage to the Schwann cell-myelin sheath, and destruction of entire nerve fibres as shown in preparations stained for axis cylinders, and by endoneurial fibrosis. The latter type of Wallerian-like destruction has been illustrated many times since the accounts of Virchow (1864), Gerlach (1891), and Lie (1894). The former type of disorder, a demyelinating neuropathy, hass been suspected on clinical grounds only because $8 \mathrm{f}^{\infty}$ the transient nature and rapid reversibility of someo lesions (Browne, 1965), and the very slow condus tion velocities and other electrophysiologivio observations made in a few cases (for example, $\stackrel{?}{0}$ Jopling and Morgan Hughes, 1965; Rosenberg amdo Lovelace, 1968). However, as discussed at length Fy Lumsden (1964), the exact pathological nature offe the nerve lesions of leprosy has remained uncertain. Earlier reports-for example, Lie (1894)-describedo patchy loss of myelin sheaths in histological sections, but subsequent observations have concentrated on the undoubted damage to axis cylinders and complete degeneration of nerve fibres, as this has been $\bar{D}$ the only type of pathological lesion which could clearly be demonstrated by the histological methods? employed. The present report appears to be the first occasion on which the hypothesis of selective Schwann cell damage has been verified by findingthe appropriate morbid anatomical lesions.

We consider that the peripheral nerve damage in our patient was due to lepromatous leprosy, but

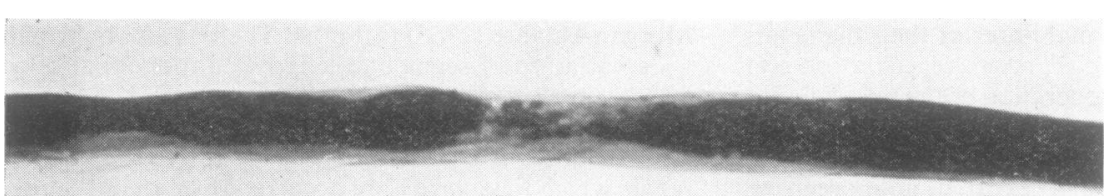

FIG. 3(a) Paranodal damage to the myelin sheath of a teased nerve fibre. Osmic acid, $\times 400$. 


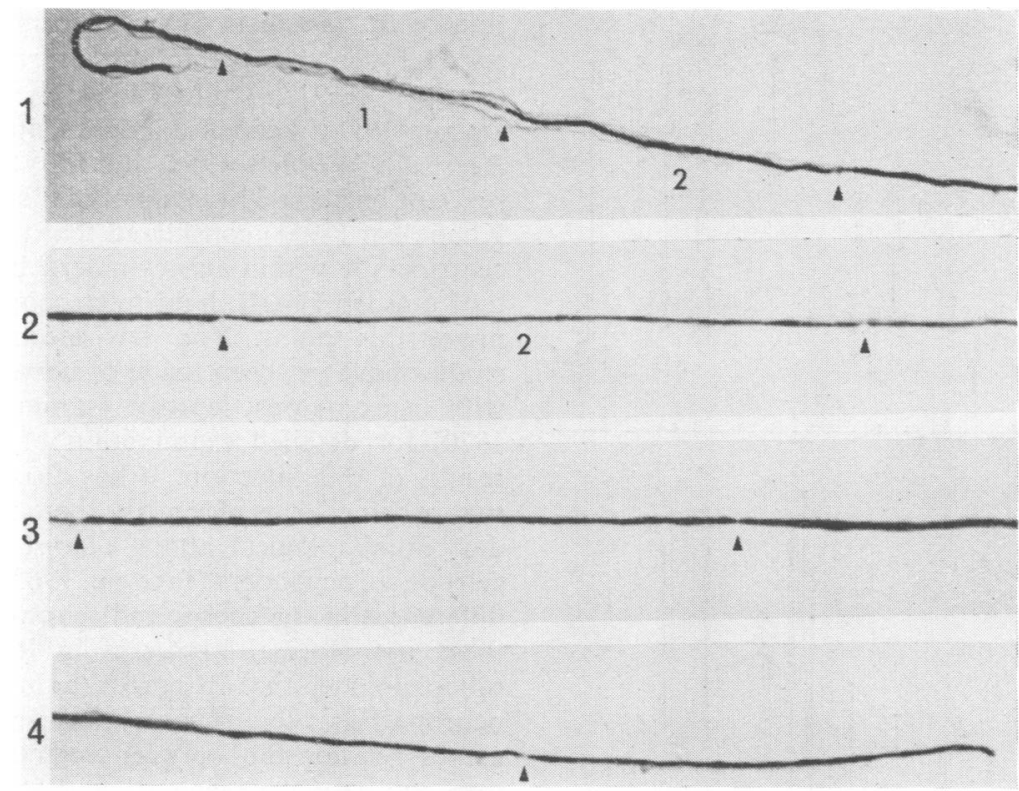

(b)

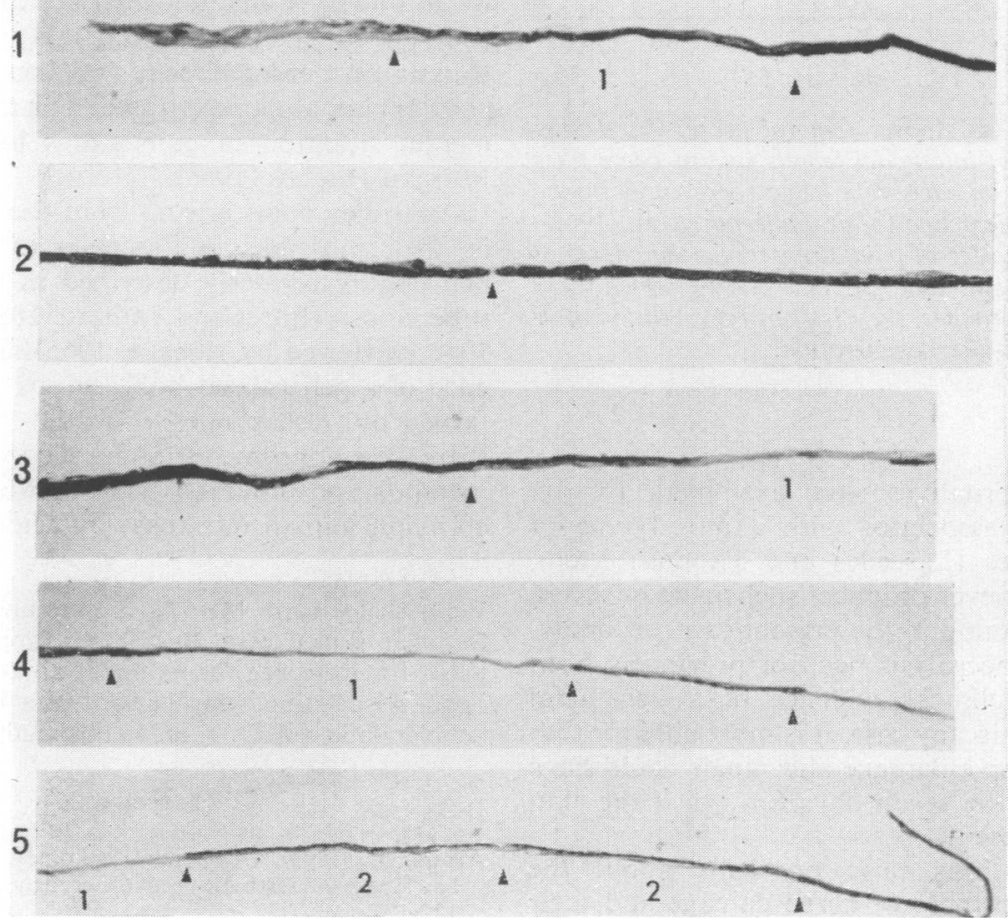

(c)

FIG. 3(b) and (c). (b) Above and (c) below: isolated nerve fibres showing internodal segments of variable length and thickness due to de-and remyelination. Nodes of Ranvier are marked by arrows. Segments ' 1 ' show remyelination as short, weakly-stained internodes, and those labelled '2' show later stages in healing. 


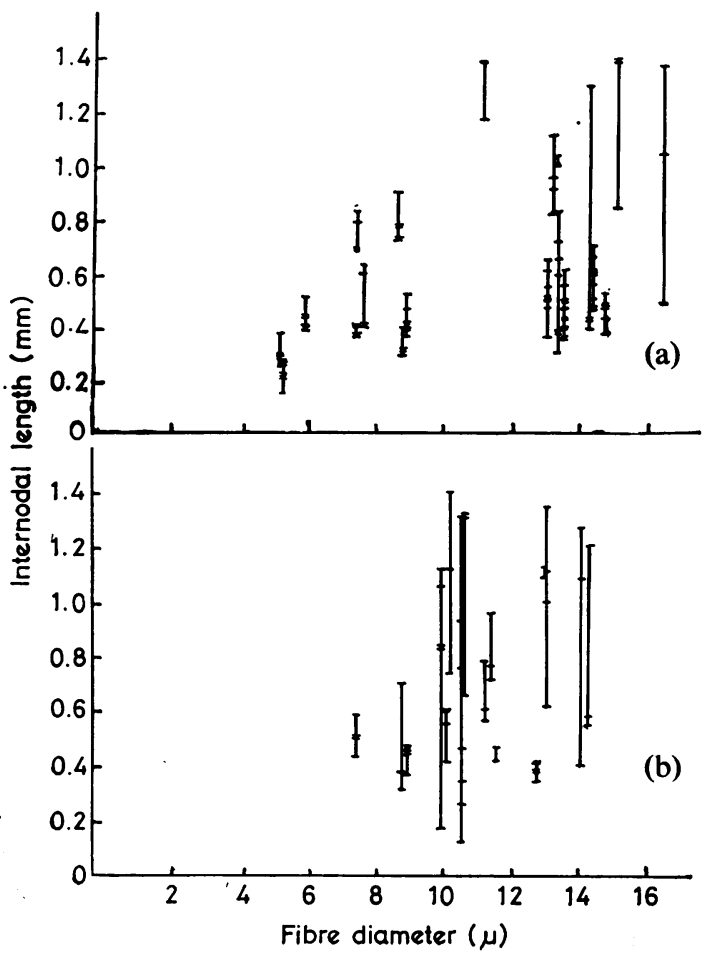

FIG. 4(a) and (b). (a) Above: femoral nerve. (b) Below: sciatic nerve. Plot of internodal length against nerve fibre diameter, segments on each fibre being represented by the points on each vertical line (after Fullerton et al., 1965) The considerable scatter of points represents the effects of de- and remyelination, and, in those fibres which bear uniformly short internodes, the result of regeneration after complete Wallerian-like degeneration.

two possible alternatives were examined. Firstly, old age itself is associated with a mixed type of damage to nerves (Lascelles and Thomas, 1966), but on its own it never produces such acute or severe lesions as those found in the present case; secondly, toxic epidermal necrolysis has not previously been associated with clinical evidence of a peripheral neuropathy, and, in any case, it is most unlikely that such extensive nerve damage and repair could have occurred during the seven days for which the skin disorder was present.

These observations raise problems about the causes of the two types of nerve damage and their relationship to each other. The most straightforward explanation would be that the cellular destruction was caused by some effect of intracellular bacilli on the metabolism and functioning of Schwann cells and axons. Although the occurrence and prolifera- tion of M. leprae in Schwann cells has been illus $Z$ trated for many years both in vivo and in vitro (Gerlach, 1891; Arning, 1894; Khanolkar, 1951 in Dastur, 1955; Weddell, Jamieson, and Palmer, 1964. Reese and Weddell, 1968; and Job, 1970), the occur $=0$ rence of bacteria within axis cylinders is less certain.? Khanolkar (1951) considered that the bacilli sprea@. centripetally within axis cylinders, but, as discussecf by Lumsden (1964), light microscopy alone cannot prove this point. Too few electron microscope studies have yet been made of nerves from patients with lepromatous leprosy (summarized by Job등 1970) for detailed examination of the extent and results of this infection. It has also been suggestech that in some forms of leprosy there may be a secondary immunological attack against either Schwannws cells or axis cylinders (Browne, 1965). There may beo differences in the causes and relative importance of these pathological processes in lepromatous and $\vec{\omega}$ tuberculoid leprosy. In leprosy, as in other peripheraf neuropathies, there is uncertainty about the possible causal relationship between segmental demyelination and axonal degeneration. Both Schwann cellse and axons might be damaged directly by the bacilfi, by secondary immunological attack and even by superadded effect of mechanical (or other forms) trauma on nerves already 'weakened' by Schwanncell damage, as demonstrated in an analogous expe mental situation in guinea-pigs by Hopkins agdof Morgan-Hughes (1969).

A further point arising from the present findings is their possible relationship to the peripherian neuropathy formerly described in association with ${ }^{\circ}$ tuberculosis (Pitres and Vaillard, 1883; Rachmanow, 1912; reviewed by Krücke, 1955). Should the existence of a generalized 'tuberculous neuritis' be con- $\bar{\partial}$ firmed by fresh studies, it would be remarkable ifo there were not some aetiological connection (perhaps ${ }_{\Omega}^{\Phi}$ metabolic or immunological) between the two most $\Rightarrow$ common human infections by acid-fast bacilli.

We wish to thank Miss M. Stokes and Mr. J. A. Mills for their skilled help, the British Empire Cancer Campaign for Research for its financial aid, and the AngloIsrael Association whose award of a Wyndham Deedes:Scholarship to A.D.D. made this study possible.

\section{REFERENCES}

Arning, E. (1893). Ueber das Vorkomen den Bacillus leprae음 bei leprae anaestheticae sive nervorum. Virch. Arch., 97, 120-121.

Browne, S. G. (1965). Some less common neurological findings in leprosy. Int. J. Leprosy, 33, 881-891.

Cochrane, R. G. (1964a). The history of leprosy and its spread throughout the world. In: Leprosy in Theory and Practice, pp. 1-12. Edited by R. G. Cochrane and T. F.N Davey. Wright: Bristol. 
Cochrane, R. G. (1964b). Signs and symptoms. In: Leprosy in Theory and Practice, pp. 251-279. Edited by R. G. Coshrane and T. F. Davey. Wright: Bristol.

Dastur, D. K. (1955). Cutaneous nerves in leprosy. Brain, 78, 615-633.

Dayan, A. D. (1967). Peripheral neuropathy of metachromatic leucodystrophy. J. Neurol. Neurosurg. Psychiat., 30, 311-318.

Fullerton, P. M., Gilliatt, R. W., Lascelles, R. G., and Morgan-Hughes, J. A. (1965). The relation between fibre diameter and internodal length in chronic neuropathy. J. Physiol. (Lond.), 178, 26-28P.

Gerlach, W. (1891). Die Beziehungen zwischen Hautflecken und der Nervenerkrankungen bei der Lepra anaesthetica. Virch. Arch., 125, 126-145.

Hopkins, A. P., and Morgan Hughes, J. A. (1969). The effect of local pressure in diphtheritic neuropathy. J. Neurol. Neurosurg. Psychiat., 32, 614-623.

Job, C. K. (1970). Mycobacterium leprae in nerve lesions in lepromatous leprosy. Arch. Path., 89, 195-207.

Jopling, W. H., and Morgan Hughes, J. A. (1965). Pure neural tuberculoid leprosy. Brit. med. J., 2, 799-800.

Khanolkar, V. R. (1951). Studies in the histology of early lesions in leprosy. Spec. Rep. Ser. No. 19. Indian Council for Medical Research: New Delhi.

Khanolkar, V. R. (1964). Pathology of leprosy. In: Leprosy in Theory and Practice, pp. 125-151. Edited by R. G. Cochrane and T. F. Davey. Wright: Bristol.

Krücke, W. (1955). Erkrankungen des peripheren Nervensystems. Lepra. In: Handbuch der speziellen pathologischen Anatomie und Histologie, Vol. XIII/5, pp. 156-160. Edited by F. Henke, R. Rössle, and $O$. Lubarsch. SpringerVerlag: Berlin.

Lascelles, R. G., and Thomas, P. K. (1966). Changes due to age in internodal length in the sural nerve in man. $J$. Neurol. Neurosurg. Psychiat., 29, 40-44.

Lie, H. P. (1894). Zur pathologischen Anatomie der Lepra. Arch. Derm. Syph. (Berl.), 29, 339-354.

Lumsden, C. E. (1964). Leprosy and the Schwann cell in vivo and in vitro. In: Leprosy in Theory and Practice, pp. 221250. Edited by R. G. Cochrane and T. F. Davey. Wright: Bristol.

Pitres, A., and Vaillard, L. (1883). Contribution à l'étude des névrites périphériques non traumatique. Arch. Neurol. (Paris), 6, 180-203.

Rachmanow, A. (1912). Zur normalen und pathologischen Histologie der peripheren Nerven des Menschen. $J$. Psychol. Neurol. (Lpz.), 18, 522-545.

Reese, R. J. W., and Weddell, A. G. M. (1968). Experimental models for studying leprosy. Ann. N.Y. Acad. Sci., 154, 214-236.

Rosenberg, R. N., and Lovelace, R. E. (1968). Mononeuritis multiplex in lepromatous leprosy. Arch. Neurol. (Chic.), 19, 310-314.

Virchow, R. (1864). Die krankhaften Geschwülste. Vol. 2. Hirschwald: Berlin.

Weddell, A. G. M., Jamieson, D. G., and Palmer, E. (1964). Recent investigations into the sensory and neurohistological changes in leprosy. In: Leprosy in Theory and Practice, pp. 205-220. Eđited by R. G. Cochrane and T. F. Davey. Wright: Bristol. 